\title{
1. Introduction to virtual worlds and gambling
}

'All our lauded technological progress - our very civilization - is like the axe in the hand of the pathological criminal'.

Albert Einstein ${ }^{1}$

The aim of this book is to provide a critical discussion on the laws and regulation relating to gambling in virtual worlds and relating to 'inworld' (contained within the virtual world) games which could constitute gambling. Gambling is a very old phenomenon but with the introduction of the Internet in the early 1990s, and the advancement of technology to allow social interaction and money transfers over the Internet, gambling has seen a new avenue to colonize. The law in this area has not kept pace with the rapidly changing technology. When the law does try to keep pace, it has been found within this research that grey areas of concern are left undiscussed and therefore unregulated. Virtual world gaming is one such grey area. There is ambiguity over whether gambling takes place within virtual world games and if it should be regulated in the same way as remote or Internet gambling. However, what is clear is that 'gambling like activities in social games and other online media has increased dramatically', ${ }^{2}$ so much so that a new term, 'gamblification', ${ }^{3}$ has been coined.

Remote or Internet gambling is a recognized and often hotly debated avenue of gambling. Different countries view remote gambling in different ways and regulate accordingly. Virtual world gaming is one further step inside the ether of the Internet. Virtual world games or games played through the medium of the Internet pose another layer of debate for regulators. First and foremost, there must be consensus as to whether

A. Calaprice, The Quotable Einstein (Princeton University Press, 1996).

J. Gatto, Gamification (Pillsbury Law, 2013).

Ibid. 
virtual worlds and online games can constitute gambling. An investigation into whether virtual world games and online games can be considered as perpetrating gambling will be carried out within this book.

This book not only considers whether virtual world games or online games can be considered to constitute gambling, but also whether financial crime, such as money laundering, is being committed through these unregulated avenues. Money laundering and terrorist financing is an ever-increasing problem and the Internet is being used more frequently as a means of laundering 'dirty' money. Criminals will always find new and innovative ways of committing criminal acts, and because of the bifurcation of opinion as to whether (a) gambling is carried out in virtual world games and online games, and (b) whether money laundering is committed through gambling on virtual world games and online games, there is little if any regulation to prevent criminals using this avenue for criminal intent.

This book will therefore provide a critical literature review of the law within the areas of virtual world and online games gambling and money laundering, through content analysis and comparative analysis. Empirical research will also be conducted to demonstrate the practical realities of gaming licences and the restrictions placed upon virtual world games and online games. However, before moving further into the discussion, it is important to provide clear definitions of terms and terminology used within this book to ensure clarity of argument as it progresses.

The main aim of this monograph is to assert that law is slow to keep pace with the changing and evolving technology advances that occur within our society. Furthermore, when the law tries to regulate and control such advances, the law uses language and terminology which is unfit for purpose. By utilizing terms such as 'fantasy', 'virtual', 'games', the actions that occur within the virtual world, Internet or game are not considered as serious. When there are serious breaches of the law within the virtual world, Internet or game, the lack of a sensible approach to the issue results in many of the crimes going unpunished. Where law enforcement agencies do attempt to prosecute, then it is the judiciary which raises issues of jurisdiction. This messy and complex world of cyber law needs to be taken seriously, with accurate definitions of crimes and issues occurring within the virtual world. Legislators, law enforcement agencies and academics must agree to view criminal acts in the Internet, virtual world and games as serious offences that affect realworld people. This book is not arguing that there needs to be a total overhaul of existing legislation, nor is it asking for new laws to be put in place. It is an attempt to persuade people to consider the issue of criminal acts within the Internet, virtual world or games as a real issue, and 
proposes some solutions and recommendations to these inadequacies of current legislation. The discussion could have focused on various aspects of criminal acts within virtual worlds, the Internet and games, but the chosen focus is on gambling within virtual worlds and the financial crime associated with the lack of regulation. Therefore, the aim is twofold: to ascertain whether virtual worlds and games are aware that gambling is taking place, and whether legislation in various countries regulates gambling. Secondly, the book looks at where financial crime could occur when gambling does take place in virtual worlds and games, and at how legislators manage to regulate the virtual world.

\section{BACKGROUND}

The latter decades of the twentieth century and the early part of the twenty-first have seen the development of more and more sophisticated virtual worlds. Advances in technology have facilitated the fast paced development of the Internet, computer processing power and graphics; this has allowed for the creation of both realistic and fanciful virtual worlds, attracting millions of Internet users. The increased numbers of users and improved infrastructure have led to increasingly complex worlds in which some users have amassed significant real world wealth through virtual world economies. Commerce within virtual worlds has given rise to questions over the involvement of the law, ${ }^{4}$ most prevalently in intellectual property law. ${ }^{5}$ This book, however, seeks to assess criminal law and its potential role in the virtual world, if indeed it has a role to play. Virtual worlds will be defined and a brief history of their development will be given. Role playing games have been around in one form or another for many years but the development of computers has arguably increased their popularity. ${ }^{6}$ The characteristics of criminal law will be analysed, particularly the potential for crimes to be committed within virtual worlds. It will be seen that the rules of games and the fact that

4 Orin S. Kerr, 'Criminal Law in Virtual Worlds' (2008) Chi. Legal F 415 and Edward Castronova, 'The Right to Play' (2004) 49 NYL Sch. L Rev. 185.

5 See Max Vern, 'Second Life: A New Dimension for Trademark Infringement' (2008) 90 J Pat. and Trademark Off Soc'y 51; Christopher Varas, 'Virtual Protection: Applying Trade Mark Law within Virtual Worlds such as Second Life' (2008) 19(1) Ent. LR 5; and Ben Quarmby, 'Pirates among the Second Life Islands: Why You Should Monitor the Misuse of Your Intellectual Property in Online Virtual Worlds' (2008) 26 Cardozo Arts and Entertainment LJ 667.

6 BBC News, 'Online games market still growing', 24 March 2009, available at http://news.bbc.co.uk/1/hi/technology/7960785.stm. 
criminal law developed in the physical world ${ }^{7}$ means that criminal law has a limited role to play in virtual worlds. Instead, the rules of the virtual worlds should be applied first under the 'magic circle' principle (see further below). ${ }^{8}$

\section{Development of Virtual Worlds}

Castronova defines a virtual world as a computer program with three defining features: 'interactivity', 'physicality' and 'persistence'. ${ }^{9}$ Users must be able to access the world remotely; it must be a simulation of a first-person physical environment; and finally, it should continue to run whether anyone is using it or not. ${ }^{10}$ This is true of modern virtual worlds but original text-based virtual words lacked physicality in the way seen today - the physicality element was in the imagination of the user. The most important elements are arguably interactivity and persistence persistence in particular, as it distinguishes virtual worlds from computer games and simulations: the virtual world continues to function even when the user logs off and it can be affected by an infinite number of users. The Federation of American Scientists (FAS) echoes the 'persistence' and 'interactivity' requirements of the Castronova definition, but adds that the interaction should be 'multi-user' and 'immediate', which can be seen as subcharacteristics of 'interactivity': simply that it must be with other non-computer operated users and this should be in real time (which additionally incorporates Castronova's 'physicality' requirement). FAS's definition also requires the program to be 'avatar-based' in that users explore the world with their avatar (this can also be seen as an extrapolation of Castronova's 'physicality').

Role playing and simulation have been around for millennia; Lastowka dates simulation back as far as Ancient Greece. ${ }^{11}$ The movement of role playing games (RPGs) to Internet environments was not surprising, and Brenner sees the basis of many early RPGs stemming from the game

7 As Brenner has identified, the law has evolved to deal with the physical world: Susan Brenner, 'Fantasy Crime' (2008) 11(1) Vand. J Ent. and Tech. L 1.

8 Johan Huizinga, Homo Ludens: A Story of the Play-Element in Culture (Beacon Press, 1938).

9 Edward Castronova, Virtual Worlds: A First Hand Account of Market and Society of the Cyberian Frontier (SSRN, 2001).

10 Ibid.

11 Gregory Lastowka, Virtual Justice: The New Laws of Online Worlds (Yale University Press, 2010) p. 31. 
Dungeons and Dragons. ${ }^{12}$ The early games were known as multi-user dungeons (MUDs); these were largely text-based and developed during the 1970s. ${ }^{13}$ Also developing were non-game environments described as multi-user object oriented (MOO), ${ }^{14}$ such as LambdaMOO. ${ }^{15}$ Text-based networks soon developed to become first-person graphical environments as computer graphics improved, along with the ability of the Internet to deal with increased traffic, especially with the increased access to broadband Internet. ${ }^{16}$

These 3D graphic-based environments are described as 'virtual worlds' and like their text-based predecessors they come in a variety of forms dependent on the individual program and the objectives the user must work towards. The broadest categories of virtual worlds are 'game worlds' and 'open worlds'. ${ }^{17}$ Game worlds provide users with objectives; they are competitive and the user's aims include improving their characters' 'level' 18 and collecting items they can equip their character with. This is achieved though completing tasks often known as quests; many game worlds include a fighting element - users may fight each other and can take items from a defeated opponent. ${ }^{19}$ Open worlds are not objective orientated, they are merely simulations, be that of the real world or a fantasy world. Second Life is a prominent open world; users create an 'avatar' 20 which they may customize and use to explore the virtual world. ${ }^{21}$ Users are free to do whatever they choose, hence the term 'open world' - they may purchase land, create in-world objects and trade amongst each other.

Brenner, 'Fantasy Crime', n. 7 above, 20.

Ibid.

14 Brendan James Gilbert, 'Getting to Conscionable: Negotiating Virtual Worlds' End User License Agreements without Getting Externally Regulated' (2009) 4(4) JICLT 238.

15 Ibid.

16 Rónán Kennedy, 'Law in Virtual Worlds' (2009) 12(10) J Internet Law 3.

17 Castronova, 'The Right to Play', n. 4 above.

18 Increasing the level of your character will often increase its attributes, health points for example or attacking/defensive strength.

19 The precise workings of player vs player combat differ between games; this description is based on the game World of Warcraft: See WoW Wiki, 'Player vs Player', www.wowwiki.com/Player_vs._Player.

20 An avatar is a 3D representation which a user controls in a virtual world; users may edit their avatar to look however they like.

21 Second Life, 'What is Second Life', http://secondlife.com/whatis/?lang= en-US. 
Trade is a common feature of most virtual worlds, predominantly via in-world currency. Users create or acquire objects and often gain surpluses of common items and may lack rare ones. This, much like the development of real-world currency, requires a commodity with standard value with which people may trade, as this relieves the limits of bartering. Castronova argues that the size of the user base and the economies of virtual worlds justify a legal assessment of virtual worlds, ${ }^{22}$ demonstrating the social importance of virtual worlds and as such the potential need for an assessment of the law's role. Law is reactive, and if such a great volume of people are participating in behaviour, producing such a high value of economic worth, it is right for the law to address the problems that may exist and the potential problems that may develop.

\section{Criminal Law}

Criminal law is the strongest tool a state possesses in relation to controlling and punishing members of society. Criminal law takes the form of the state against the individual, and permits the strongest sanctions available to the courts; in the majority of the developed world this is incarceration, but a declining number of countries still impose capital punishment. ${ }^{23}$ A crime is made up of four elements: the actus reus, the mens rea, causation and harm: ${ }^{24}$ to be guilty of a criminal offence a person must perform the act, intending to do so and that act must cause harm. Under the UK legal system, the above four elements must be proved to a jury beyond reasonable doubt in order for them to come to a guilty verdict.

Criminal law has been categorized by Brenner based on the harm caused by the offence: hard harms and soft harms. ${ }^{25}$ Hard harms are seen as traditional offences - physical harm against another human, be that murder, rape, other bodily harm or theft and damage to property. Soft harms are non-physical wrongs the law has addressed - offences against harming 'morality', 'affectivity' or causing 'systemic' harm. ${ }^{26}$ Brenner

22 Castronova, Virtual Worlds, n. 9 above.

23 In-depth analysis into the use of the death penalty has been carried out by Amnesty International: Amnesty International, 'Death Sentences and Executions in 2012', available at www.amnesty.org/en/library/asset/ACT50/001/2013/en/ bbfea0d6-39b2-4e5f-a1ad-885a8eb5c607/act500012013en.pdf.

24 Andrew Ashworth, Principles of Criminal Law (Oxford University Press, 2009).

25 Brenner, 'Fantasy Crime', n. 7 above.

26 Ibid. 8. 
argues offences against morality to include the possession and abuse of substances or breaching gambling legislation; these crimes do not directly harm another individual but are against the 'moral sense of the community'. 27 'Affectivity' harms are non-physical harms to individuals, be that to their reputation through the offence of libel, ${ }^{28}$ or to their security through harassment or stalking. ${ }^{29}$ 'Systemic' harms are harms to the system and can be described as regulatory offences such as failure to pay tax or fulfil legal obligations. ${ }^{30}$

\section{Affectivity}

Despite their sophistication it is difficult to imagine regulatory offences being committed in virtual worlds. It is, however, reasonable to hypothesize circumstances where Brenner's 'morality' and 'affectivity' harms might occur through actions within virtual worlds. Taking 'affectivity' first: it is established law that harassment can be committed via telephone calls under the widely worded Protection from Harassment Act (PHA) $1997,{ }^{31}$ and it has been held that even if those phone calls are silent such behaviour is capable of causing actual bodily harm. ${ }^{32}$ PHA 1997 was amended in 2012 to include the offence of 'stalking' under s.2A, ${ }^{33}$ which specifically refers to monitoring use of 'the Internet, email or any other form of electronic communication'. ${ }^{34}$ While this only refers to the 'monitoring' of a person, other offences under PHA 1997 are interpreted widely, as observed by Gillespie. ${ }^{35}$ The term 'course of conduct' 36 should enable the wording of $\mathrm{s.4}$ 'putting people in fear of violence' 37 to be carried out via a virtual world, provided the conduct causes a reasonable person to fear such violence. Brenner observes that this is the appropriate check, a standard to adhere to, judged against an 'objective ascertainable harm' 38 and negating prosecutions based on the 'idiosyncrasies of a

27 Lawrence Freidman, Crime and Punishment in American History (Basic Books, 1934).

28 Brenner, 'Fantasy Crime', n. 7 above, 10.

29 Ibid. 12

30 Ibid. 17.

31 Protection from Harassment Act 1997.

$32 \quad R$ v Ireland [1996] 3 WLR 650.

33 Protection from Harassment Act 1997, s.2A.

34 Ibid.

35 Alisdair Gillespie, 'Cyberstalking and the Law: A Response to Neil MacEwan’ [2013] 1 Crim. LR 38.

36 Protection from Harassment Act 1997, s.4.

37 Ibid.

38 Brenner, 'Fantasy Crime', n. 7 above, 16. 
particular individual'. ${ }^{39}$ Despite the amendments to the law, MacEwan still argues the law does not go far enough to address cyberstalking. ${ }^{40}$

Harassment law in the United Kingdom addresses the 'soft harm' identified by Brenner, but the reasons behind this development have been questioned in the United States of America. Brenner traces the stalking offences back to a collection of high profile murders in the 1980s, including that of Rebecca Schaeffer, who was stalked and killed, prompting legislators to react. ${ }^{41}$ This led to some characterizing stalking as an inchoate offence progressing to 'hard harm' and the offence of stalking is merely a preventative offence addressing the greater physical harms that could follow. Brenner dispels this notion, considering stalking to cause a distinct soft harm. ${ }^{42}$

Libel is another affective soft harm explored by Brenner, ${ }^{43}$ and again this offence has been used to prevent future 'hard harm' occurring; libellous harm, without legal recourse, could lead to duelling and physical fights. Libel is no longer a criminal offence; it is now a civil offence. Where libel is concerned with incorrect information, superinjunctions concern private information; the information concerned may be correct but the holder of the injunction wants it kept private. Breaching a super-injunction can incur criminal liability, as the offender will be in contempt of court ${ }^{44}$ and face an unlimited fine or a prison sentence. ${ }^{45}$ This may be imposed for what is ultimately a 'soft harm' - no physical harm occurs. This 'soft harm' of damaged reputation must be recognized and like harassment can surely be committed in virtual worlds: statements and representations can easily be made within a virtual world, which could have a detrimental effect on the victim. The recent issues with super-injunctions demonstrate the most prevalent issue in pursuing crime in virtual worlds: the anonymity of the users. This issue is best demonstrated using the micro-blogging website Twitter, ${ }^{46}$

39 Ibid.

40 Neil MacEwan, 'The New Stalking Offences in English Law: Will They Provide Effective Protection from Cyberstalking?' [2012] 10 Crim. LR 767.

41 Andrea Robinson, 'A Remedial Approach to Harassment' (1984) 70 VA L Rev. 507.

42 Brenner, 'Fantasy Crime', n. 7 above, 16.

43 Ibid.

44 Ursula Smartt, 'Twitter Undermines Super Injunctions' (2011) 16(4) Comms L 135.

45 Ibid.

46 Twitter users may follow one another's 'tweets' to stay in touch with their activity and news stories from various media accounts. Each tweet is strictly 
which has caused controversy through users publishing sensitive information. ${ }^{47}$ One such example occurred on 9 May 2011, when a Twitter account published details of several individuals in the public eye who had taken out super-injunctions; the most prominent example was a footballer who was alleged to have committed adultery with a former reality TV show contestant. ${ }^{48}$ The Twitter user used a pseudonym and as such could not be identified; users are required to submit their name, an email address and a password, ${ }^{49}$ and no checks are undertaken to ensure the user gives their real name. Once the information is on the Internet it is impossible to contain; many users 'retweeted' the initial publication and an indeterminable number of people may have viewed the information. This situation could easily be transferred to a virtual world: users are required to provide similar details to those required by Twitter and false information may easily be accepted. Following this, a user may pass on information to other users via in-game messaging. This information could place the user in contempt of court but they could not be pursued as their identity would not be known. However, a successful prosecution for contempt of court through social networks occurred as recently as April 2013, when two suspended sentences were handed down for users releasing information concerning the new identities of James Bulger's killers. ${ }^{50}$

\section{Morality}

Brenner's morality category can be distinguished from affectivity harms though their victims: affectivity harms cause soft harm to an identifiable individual; morality crimes have been labelled as victimless, ${ }^{51}$ the harm being a breach of societal values. Examples used by Brenner include gambling and substance abuse. Substance abuse does not readily transfer to virtual worlds - no known drug can be administered via a virtual world.

limited to 140 characters. For further details see Twitter, 'About Twitter', https://twitter.com/about.

47 'Twitter account challenges super-injunctions', Financial Times online, 9 May 2011, www.ft.com/cms/s/0/70393786-7a82-11e0-8762-00144feabdc0.html \#axzz2RI4fIAzg.

48 Smartt, 'Twitter Undermines Super Injunctions', n. 44 above.

49 Twitter, 'Join Twitter Today', https://twitter.com/signup.

50 BBC News, 'Bulger killers' images: two receive suspended sentences', 26 April 2013, available at www.bbc.co.uk/news/uk-22310412.

51 Brenner, 'Fantasy Crime', n. 7 above. 
Gambling can take place via the Internet, as the wide array of online casinos shows, ${ }^{52}$ and has proved problematic in popular virtual worlds in countries which prohibit gambling. Linden Labs prohibit gambling within Second Life; ${ }^{53}$ the ban was introduced in 2007 after investigations by the $\mathrm{FBI}^{54}$ in the United States of America, where online gambling is illegal. Second Life was perhaps distinguished from other virtual worlds as it was known to contain casinos which were easily found. ${ }^{55}$ In relation to game-based virtual worlds, it has been argued that many of them can be classified as a game of chance under s.6 of the (UK) Gambling Act $2005^{56}$ and should therefore be regulated by gambling legislation. ${ }^{57}$ This is a debate for another book, but demonstrates a soft harm where gambling is prohibited.

A further morality offence can be seen in the possession of indecent images of children. This crime is not victimless - the children in the images are victims of sexual abuse. This crime, like the vast majority of crimes, existed prior to the Internet but the increased spread of such material has been facilitated by the development of the Internet. This link has been apparent for some time. The US Attorney General's report of 1986 claims paedophile rings were already using the Internet to exchange information. ${ }^{58}$ Clough highlights the relatively low cost of the required technology, the ease of access and its portability as potential reasons for paedophiles utilizing computer networks; additionally the images can now be produced without the need for external processing, as digital photos do not need to be developed as photo film does. ${ }^{59}$ Unlike other

52 For examples see 32Red, '32Red Online Casino', www.32red.com/; Gala Casino, 'Gala Casino Home', www.32red.com/; and William Hill, 'William Hill Casino Club', www.williamhillcasino.com/.

53 Second Life, 'Linden Lab Official: Policy regarding Wagering in Second Life', http://wiki.secondlife.com/wiki/Linden_Lab_Official:Policy_Regarding_ Wagering_in_Second_Life\#Is_all_simulated_gambling_in_Second_Life_is_illegal. $3 \mathrm{~F}$.

54 Reuters, 'FBI checks gambling in Second Life virtual world', 4 April 2007, available at www.reuters.com/article/2007/04/04/us-secondlife-gamblingidUSN0327865820070404.

55 Ibid.

56 Gambling Act 2005, s.6.

57 Gamesindustry International, 'MMO Operators at Risk', www.games industry.biz/articles/mmo-operators-at-risk-of-breaking-law-from-september.

58 US Department of Justice, Attorney General's Commission on Pornography: Final Report (Rutledge Hill Press, 1986).

59 Jonathan Clough, Principles of Cybercrime (Cambridge University Press, 2010). 
illegal trades, possession alone is a criminal offence, compared to the majority of substances where the offence is supply. The judgment in $R v$ Sharpe ${ }^{60}$ summarizes the rationale for this: '[c]riminalising possession may reduce the market for child pornography and the abuse of children it often involves'. ${ }^{61}$

The accompanying development of computers and software has also increased the production and distribution of pseudo-photographs. The Protection of Children Act $1978^{62}$ defines a pseudo-photograph as 'an image, whether made by computer-graphics or otherwise, which appears to be a photograph'. ${ }^{63}$ This has been used to prosecute even where the activity does not involve children - a man was convicted for manipulating a picture of an adult woman to look like a child. ${ }^{64}$ There is a potential boundary in applying such legislation to virtual worlds; it may be argued that the images produced in a game cannot currently amount to appearing to be a photograph. Clough argues that currently no software is capable of such likeness, and the US case of United States $v$ Marchand ${ }^{65}$ failed on this basis; it could not be proved that images appearing to be photographs could be produced.

The legislation in the United Kingdom is designed to comply with the wording of the Council of Europe's Convention on Cybercrime:66 'realistic images representing a minor engaged in sexually explicit conduct' ${ }^{67}$ While this is slightly different to the US legislation, the word 'realistic' is potentially troublesome. Cornelius highlights that German law is written widely enough to criminalize 'purely fictive representations' 68 of child pornography. This approach is to address the perceived danger of those producing or viewing such material to go on to abuse children. ${ }^{69}$ This would arguably make this an inchoate offence, designed to prevent more serious misdemeanours.

\footnotetext{
$60 \quad R v$ Sharpe [2001] 1 SRC 45.

61 Ibid. per McLachlin CJ at para. 99.

62 Protection of Children Act 1978.

63 Ibid. s.7(7).

64 Andrew Norfolk, "Computer expert faces jail over "made up" child porn images', The Times (London), 10 August 2006, 30.

65 United States v Marchand, 308 F.Supp.2d 498 (D. N.J. 2004).

66 Council of Europe Convention on Cybercrime [2001] ETS 185.

67 Ibid. Art. 9(2)(c).

68 Kai Cornelius, 'Responsibility under Criminal Law in Virtual Worlds' in Kai Cornelius and Dieter Hermann (eds.), Virtual Worlds and Criminality (Springer, 2011).

69 Ibid.
} 


\section{Physical facts}

The development of the law in relation to child pornography can be used to demonstrate the limitations of criminal law in relation to virtual worlds; criminal law is predominantly concerned with the physical 'real world' and has developed taking the natural laws of physics for granted. As Kerr points out, the law does not recognize a user 'entering' a virtual world; the law recognizes an individual logging onto a server and then sending and receiving electronic communications ${ }^{70}$ - the law focuses on the physical network. ${ }^{71}$ This focus on the precise physical facts has led to problems in applying child pornography law to computer generated images. Clough notes that digital images mainly exist as data, ${ }^{72}$ unlike the physical photographs the law originally developed in relation to, which are stored as tangible images. This presents an issue when the criminalized item is a photograph: the data is not a photograph, it requires a computer to read the file and produce the image, which strictly speaking is also not a photograph in the traditional form. This has been addressed in UK law. An amendment to the Protection of Children Act 1978 widens the definition of the word 'photograph' to include 'images, whether made by electronic or other means', ${ }^{73}$ which is to include data stored on a computer disk which can be converted into an image. ${ }^{74}$ Such representations have not been extended to other sexual offences; for example, Kerr stipulates that virtual rape is not rape because no one is physically violated, arguing this is just a story of rape. ${ }^{75}$

\section{Virtual crime}

The term 'virtual crime' has come to be commonly used by commentators. ${ }^{76}$ Virtual crime is a peculiar term because it appears to detract from the seriousness with which crime should be considered. The Oxford Dictionary defines virtual as 'almost or nearly as described, but not completely or according to strict definition', ${ }^{77}$ and in relation to computing "not physically existing as such but made by software to appear to do

\footnotetext{
70 Kerr, 'Criminal Law in Virtual Worlds', n. 4 above.

71 Ibid.

72 Clough, Principles of Cybercrime, n. 59 above, p. 265.

73 Protection of Children Act 1977, s.7(4A)(a).

74 Ibid. s.7(4A)(b).

75 Kerr, 'Criminal Law in Virtual Worlds', n. 4 above, 418.

76 See Gregory Lastowka and Dan Hunter, 'Virtual Crimes' (2004) 49 NYL Sch. Rev. 294 and Brenner, 'Fantasy Crime', n. 7 above.

77 Oxford Dictionaries, 'Virtual', available at http://oxforddictionaries.com/ definition/english/virtual?q=virtual.
} 
so' ${ }^{78}$ When considered in relation to the most powerful action a state can take against an individual, it can be seen to detract from criminal law's importance. The curious case of Mr Bungle led many to consider the potential for crimes to be considered in the virtual world, but this also led to the term 'virtual rape' which Kerr dismisses. Mr Bungle was the name of a character adopted by a user in an early text-based environment, LambdaMoo MUD. Mr Bungle forced other characters to perform sexually explicit acts, describing them in the text-based world. ${ }^{79}$

Lastowka and Hunter rightly observe that the term 'virtual crime' will be meaningless if applied to all computer-based depictions of crime, such as the Mr Bungle case. Lastowka and Hunt fear the word 'virtual' is losing its meaning due to its over-use, citing 'virtual reality', 'virtual pets', 'virtual bookstores', and even turning on Microsoft's (since retired) animated paperclip known as the 'virtual assistant'. Marie-Laure Ryan ${ }^{80}$ argues that 'virtual' is becoming virtually meaningless, in an attempt to remind readers of its former use. Cornelius proposes the use of a new word, 'virtureal', to describe acts in virtual worlds which have injurious effects in the real world. ${ }^{81}$ Although a fine idea, it can be argued that if an already existing word is causing issues, a new one is likely to add confusion and potentially further prevent such crime being taken seriously. Arguably, crime in virtual worlds should be considered as cybercrime: crime committed against a computer or using a computer. ${ }^{82}$

\section{POLICING VIRTUAL WORLDS}

Activity in virtual worlds, when broken down to its physical actions, is simply the movement of electronic signals between various users and servers in order to produce the images on their screens; this severely limits the offences one can commit in virtual worlds. Additionally, those who do not have experience of virtual worlds can be sceptical of their

\footnotetext{
78 Ibid.

79 Julian Dibbell, My Tiny Life: Crime and Passion in a Virtual World (Holt Paperbacks, 1999).

80 Marie-Lure Ryan, Cyberspace Textuality: Computer Technology and Literary Theory (Indiana University Press, 1999).

81 Cornelius, 'Responsibility under Criminal Law in Virtual Worlds', n. 68 above.

82 Lastowka and Hunter, 'Virtual Crimes', n. 76 above and Brenner, 'Fantasy Crime', n. 7 above.
} 
importance and value. Geoff Luurs found his Final Fantasy XI ${ }^{83}$ account had been hacked and his items and currency had been stolen. Luurs reported this to police in Blaine, Minnesota, who refused to investigate the case, despite Luurs explaining he had taken four years to collect the items which were worth an estimated US $\$ 3,800$. The police did not accept that the items had any value and so no theft had taken place. ${ }^{84}$ This example demonstrates the limited knowledge of many people of the real value of virtual worlds, but Kerr sees little the national police can do even if they were to pursue such incidents: "A police officer in Los Angeles has very little way of helping a Los Angeles citizen who was injured by someone in Russia through a server in the Netherlands'. ${ }^{85}$ Virtual worlds lack physical boundaries; they span physical borders because they are accessible from wherever the Internet is accessible. As such, any pursuit of crime in the virtual world will have to be on an international scale. This is not impossible, but it is potentially expensive; considering the resources potentially required, Luurs' US $\$ 3,800$ loss seems small. Kerr notes that such investigations will most likely be reserved for high profile cases.

\section{What if Crime is the Aim of the Game?}

Anyone with first-hand experience of computer games, or anyone that has seen headlines in some tabloid newspapers, ${ }^{86}$ will know criminal acts are part of the gameplay of many games. Virtual worlds have continued this trend and it is difficult to see how simulating criminal acts in a game can make the user criminally liable. ${ }^{87}$ No one is harmed by a user on World of Warcraft 'killing' another user - the killed user will simply 'respawn's8 and carry on playing. Similarly, Lastowka and Hunter refer

\footnotetext{
83 Play Online, 'Final Fantasy XI Online: Game Introduction', www.play online.com/ff11 eu/intro/about/welcom.html?pageID=about.

84 John Brewer, 'When a Virtual Crook Struck This Gamer, He Called Real Cops', www.twincities.com/ci_8134692, cited in Brenner, 'Fantasy Crime', n. 7 above, 58.

85 Kerr, 'Criminal Law in Virtual Worlds', n. 4 above, 426.

86 Eddie Wrenn, 'Violent images in movies, TV or computer games CAN act as triggers for aggression, says new report', Daily Mail (London), 29 August

87 Lastowka and Hunter, 'Virtual Crimes', n. 76 above and Brenner, 'Fantasy Crime', n. 7 above.

88 'Respawning' is the term used to describe a user being placed back into the virtual world, usually in a predetermined safe zone.
} 2012. 
to the 'gruesome murder of PacMan', 89 highlighting the ridiculousness of labelling such activity criminal. Computer games are not revolutionary in permitting what would otherwise be criminal acts. Kerr notes that betting in a game of cards can result in what may appear to be theft; the winner will take the loser's money regardless of whether the loser lets them or not. ${ }^{90}$ More innocent than card games, children will play Cowboys and Indians or Cops and Robbers, simulating shooting each other, usually without anyone being hurt. Brenner proposes that establishing whether a genuine crime has been committed is a question of determining where the harm has occurred. "If the harm resulting from conduct "in" a virtual world does not bleed out into the real world', ${ }^{91}$ then there is no crime.

\section{Harm-based Approach}

It would appear that two questions must be asked in order to ascertain whether an act in a virtual world is a crime or not; first, has the act had an effect in the real world which would constitute a crime; secondly, is that act within the rules of the game.

The first question will eliminate acts that are merely representations of crimes as identified by Kerr.92 Physical harm cannot be caused by the representation of crime in virtual worlds, however soft harms do have the potential to be committed in the virtual world. In fact, harassment and stalking are arguably made easier by the development of technology, as are moral wrongs such as gambling or viewing child pornography. Few of the traditional crimes Brenner highlights will pass this test; 93 it is not possible to commit murder via acts in the virtual world, nor any other instances of physical harm. However, Brenner does consider theft a traditional crime and this can be committed via the virtual world.

The second issue to be addressed is whether or not the act is allowed within the rules of the game; it would follow that virtual worlds should be regulated as sports and games are regulated. This is consistent with the concept of the 'magic circle', first proposed by Huizinga in 1938, 94 which recommends an exclusion zone inside which the rules of the game

\footnotetext{
89 Lastowka and Hunter, 'Virtual Crimes', n. 76 above and Brenner, 'Fantasy Crime', n. 7 above.

90 Kerr, 'Criminal Law in Virtual Worlds', n. 4 above, 421.

91 Brenner, 'Fantasy Crime', n. 7 above.

92 Kerr, 'Criminal Law in Virtual Worlds', n. 4 above, 421.

93 Brenner, 'Fantasy Crime', n. 7 above.

94 Huizinga, Homo Ludens, n. 8 above.
} 
are to be followed. This is to protect the game from real-world influences, ${ }^{95}$ as well as the players; a tackle on a football pitch could easily constitute an assault otherwise. While this is true, the magic circle can only go so far; potential criminal offences outside of the rules of a sport will still be investigated by authorities, as demonstrated by the drawn-out racial abuse case in 2012 concerning the footballer John Terry. ${ }^{96}$ Based on the magic circle principle, it follows that only where the authorities are failing, the rules are inadequate, or the act is of particular severity will the law step in.

In relation to virtual worlds, this line will most likely be crossed when the impacts leak into the real world; the acts themselves will pierce the magic circle and as such become regulated by the law rather than the game. This rule will protect the users of virtual worlds from punishment for the representation of crime, but with the exceptions of child pornography and gambling. Applying this version of the magic circle to virtual worlds would not affect the law in dealing with crimes in which the computer or computer program is merely a tool to commit a crime. The most obvious example of this is money laundering: an individual using a virtual world to conceal the proceeds of crime will pierce the magic circle with his acts; the money is illegitimate when it enters the virtual world and still so when it exits. The money will be connected to a real-world crime and the act of money laundering is not within the rules of any virtual world.

Where possible, criminal law should not interfere with virtual worlds; this is because virtual worlds are predominantly used as a space to escape the real world and should remain an escape. As Kerr opines '[c]riminal law is a blunt instrument that should only be used as a last resort ... reserved for harms that other mechanisms cannot remedy'. ${ }^{97}$

Crime in virtual worlds presents difficulties for various reasons, the majority of which stem not from the games themselves but arguably over-analysis and incorrect terminology. The term 'virtual crime' proves to be particularly problematic as the word 'virtual' has been so over-used its meaning is very weak; this weakness is shown by its very selection as part of the term 'virtual crime'. Virtual crime suggests to the lay person crime that is not actually committed - it is virtually committed. This is not the case: crime committed in a virtual world is actually committed.

95 Yen-Shyany Tseng, 'Governing Virtual Worlds: Interration 2.0' (2011) 35 $J$ Law and Policy 547.

$96 \quad R$ v Terry (Westminster Magistrates, 13 July 2012).

97 Kerr, 'Criminal Law in Virtual Worlds', n. 4 above, 417. 
Crime committed in a virtual world should be labelled as cybercrime, cybercrime committed through virtual worlds.

The difficulties relating to when an act is and is not a crime have also been over-complicated. The harm-based approach to the magic circle principle would solve this issue. The actual consequences of the act should be looked to first; if criminal damage has not occurred then the issue should go no further. If actual criminal damage is identified then the rules of the game should be used first before the heavy-handed criminal law; after this assessment, if the harm is serious enough for the rules of the game to be silent then a criminal case may be mounted. On first reading, this may appear to ignore the issue of child pornography, but in relation to this, the offence is to produce, possess or view images; as such, the image appearing on the user's screen is sufficient for the effects to be outside of the virtual world.

In coming to this conclusion the physicality of the law is considered and this physicality is arguably the criminal law's limitation, but the virtual world is not the limit to actions online. Criminal offences require the impacts of actions to spill into the physical world of the criminal law. It is in the physical world where the majority of the world's population are still solely active; many people who use the Internet only use it, they do not live or act in it. This is why many people are dismissive of virtual worlds and the suggestion that they can have any impact on the real world. This is changing, however, and as more and more people enter virtual world the more widely understood they will become.

\section{DEFINITIONS}

As initially asserted, definitions play a key part in the argument put forward in this book. The assertion is that through the lack of a coherent and meaningful definition, various aspects of gambling and financial crime go unnoticed within virtual worlds and games. Therefore it is imperative to examine all aspects of the elements that are discussed in this research.

\section{Gambling}

The New Encyclopaedia Britannica defines gambling as 'the betting or staking of something of value, with consciousness of risk and hope of gain, on the outcome of a game, contest, or uncertain event the result of which may be determined by chance or accident or have an unexpected result by reason of the bettor's miscalculation'. 
The Oxford English Dictionary 2012 (online) states that gambling is 'to play games of chance for money, esp. for unduly high stakes; to stake money (esp. to an extravagant amount) on some fortuitous event', whereas Black's Law Dictionary (6th edn) defines gambling as 'gambling involves, not only chance but a hope of gaining something beyond the amount played. Gambling consists of consideration, an element of chance and reward'.

The Gambling Act 2005 provides that 'gambling' in legal terms is defined as follows:

3. Gambling

In this Act 'gambling' means:

(a) gaming (within the meaning of section 6),

(b) betting (within the meaning of section 9), and

(c) participating in a lottery (within the meaning of section 14 and subject to section 15).

\section{Remote Gambling or Internet Gambling}

Remote gambling or Internet gambling occurs where a game of chance or skill is played for the purpose or hope of winning a wager on the outcome of the game, which is played via the Internet or other remote device such as a mobile phone, video game or ipad. The player is remote from the action.

The Gambling Act 2005 defines remote gambling as follows:

4. Remote gambling

(1) In this Act 'remote gambling' means gambling in which persons participate by the use of remote communication.

(2) In this Act 'remote communication' means communication using -

(a) the Internet,

(b) telephone,

(c) television,

(d) radio, or

(e) any other kind of electronic or other technology for facilitating communication.

(3) The Secretary of State may by regulations provide that a specified system or method of communication is or is not to be treated as a form of remote communication for the purposes of this Act (and subsection (2) is subject to any regulations under this subsection). 


\section{Cybercrime and Virtual Financial Crime}

Cybercrime can be described as any criminal activity having taken place via the Internet, smart phone or other electronic means. ${ }^{98}$ Virtual financial crime is part of such cybercrime. It is where financial crimes such as fraud, money laundering, scams take place on the Internet. It forms part of the cybercrime umbrella. ${ }^{99}$

\section{Game of Skill or Chance}

A 'game of chance' has been defined as a game which 'must be governed in part by luck ... it is not possible for the player to know the outcome', whereas a 'game of skill' has been defined as a game which 'is principally determined by the knowledge or ability of each player'. 100 However, the Gambling Act 2005 contains the following definitions:

6. Gaming and game of chance

(1) In this Act 'gaming' means playing a game of chance for a prize.

(2) In this Act 'game of chance' -

(a) includes -

(i) a game that involves both an element of chance and an element of skill,

(ii) a game that involves an element of chance that can be eliminated by superlative skill, and

(iii) a game that is presented as involving an element of chance, but

(b) does not include a sport.

(3) For the purposes of this Act a person plays a game of chance if he participates in a game of chance -

(a) whether or not there are other participants in the game, and

(b) whether or not a computer generates images or data taken to represent the actions of other participants in the game.

(4) For the purposes of this Act a person plays a game of chance for a prize -

(a) if he plays a game of chance and thereby acquires a chance of winning a prize, and

(b) whether or not he risks losing anything at the game.

\footnotetext{
98 See www.cybercrime.gov.

99 C.L. Chambers-Jones, Virtual Economies and Financial Crime (Edward Elgar, 2012).

100 S. Roy and T.K. Biswas, 'Internet Gambling: Jurisdiction and Response of Indian Law' (2010) International Company and Commercial Law Review 253.
} 
(5) In this Act 'prize' in relation to gaming (except in the context of a gaming machine) -

(a) means money or money's worth, and

(b) includes both a prize provided by a person organising gaming and winnings of money staked.

(6) The Secretary of State may by regulations provide that a specified activity, or an activity carried on in specified circumstances, is or is not to be treated for the purposes of this Act as -

(a) a game;

(b) a game of chance;

(c) a sport.

\section{Internet Game, Virtual World Game and Social Networking Game}

Social gaming gambling is a game (such as massively multi-player online role play games (MMORPGs)) which allows players to enter into games of chance or skill for a prize of money or money's worth.

Social networking games can fall under the ambit of gambling due to the fact that players/users enter games of chance or skill for the prize of social network credits. Gambling has become a borderless activity. It has been stated that 'social gaming exists outside the sphere of gambling because it does not combine all components required to be classified as gambling' ${ }^{101}$

\section{Prize}

The definition of 'prize' is important for the purposes of establishing whether virtual world games and online games do carry out gambling activities. The definition of a prize includes anything of value and not necessarily money in a game of chance or skill.

\section{Money Laundering}

There has been no consensus on the definition of money laundering and therefore it is best defined for the purposes of this book as outlined in s.340(11) of the Proceeds of Crime Act 2002:

101 Marcos Charif, Harris Hagan, 'Show Me the Money: Social Games, Virtual Currencies and Gambling’ (2011) iGaming Business (March). 
(11) Money laundering is an act which -

(a) constitutes an offence under section 327,328 or $329 ; 102$

(b) constitutes an attempt, conspiracy or incitement to commit an offence specified in paragraph (a);

(c) constitutes aiding, abetting, counselling or procuring the commission of an offence specified in paragraph (a); or

(d) would constitute an offence specified in paragraph (a), (b) or (c) if done in the United Kingdom.

\section{AIMS, OBJECTIVES AND METHODOLOGY OF THE RESEARCH}

\section{Aims and Objectives}

The purpose of this book is to present the findings made through empirical, comparative and content analysis on the topic of Internet gambling, virtual worlds and economic crime. These three topics are inextricably linked by the actions of criminals perpetrating economic crimes via online gaming, either on the Internet or through virtual worlds.

Therefore, the aims of the book are as follows:

- to investigate and provide comparative findings through content analysis of remote gambling legislation in eight countries identified as being in the top ten of states involved in MMORPGs, namely: United Kingdom; United States of America; Canada; Switzerland; Japan; France; South Korea and Iceland;

- to provide a comparative analysis of economic crime legislation to determine whether such economic crime legislation and gambling legislation can prevent economic crime from occurring through gambling online (it was decided to examine only the United Kingdom, United States of America and South Korea as the main countries or origins because of the geographic reach of these countries);

- to provide content analysis of the top ten MMORPGs which promote gambling and to determine whether they comply with the

102 Under s.327 an offence is committed if criminal property is concealed, disguised, converted, transferred or removed from the United Kingdom. Under s.328, it is an offence of conspiracy for a person to enter into an arrangement which he 'knows or suspects' to involve money laundering. Under s.329, the acquisition, use or possession of criminal property is prohibited. 
gambling legislation in their respective countries and/or other jurisdictions;

- to provide comparative analysis and synthesis of the global regulations on remote gambling given the cross-jurisdictional nature of the activity and to determine whether this is effective for the prevention of economic crime.

These four aims of the research project will be depicted in the findings of this book and will be discussed in distinct sections. The methodology that has been chosen to underpin the research is comparative analysis and content analysis.

\section{Methodology}

The methodological approach of this research is that of qualitative empirical research. Empirical research involves the carrying out of unique indirect or direct observation or analysis on a particular topic. Qualitative research is where the researcher is interested in discovering the process of the phenomenon in its natural setting. In this instance, the researcher was interested in finding out about the legal environment of online gambling and economic crime. In qualitative research, there is an emphasis on the understanding, meaning and interpretation of the research; therefore in this instance, the importance of understanding how criminals use online gaming sites to perpetrate economic crimes was considered. (Quantitative research, which is research using statistics, was not used in the project.)

The methods used within this methodological approach were those of comparative analysis and content analysis. Comparative analysis is used in cross-cultural studies to identify, analyse and explain similarities and differences across society. ${ }^{103}$ This book will examine the eight main jurisdictions, and the causal similarities and differences between them will be considered. A mixture of doctrinal black-letter law analysis and soft law analysis in the form of content analysis is used when analysing the legislation of each country. Doctrinal analysis can be defined as being where legal research focuses on the constitution, statutes and case law of a particular country without giving weight to other forms of regulation, such as soft law or codes of practice. By marrying the two, we are able to analyse the whole spectrum of regulation in each country as regards gambling and financial crime. This provides a comprehensive review of

103 L. Hantrais, 'Comparative Research Methods' (1995) 13 Social Research Update (Summer), available at http://sru.soc.surrey.ac.uk/SRU13.html. 
the legal and regulatory perspective for each country, and by using comparative analysis we are also able to show the similarities and differences in each jurisdiction. This is particularly important because the Internet is boundary-less; it pervades all jurisdictions and is able to cross national borders. This empirical research demonstrates where there are serious gaps in the law for criminals to abuse and commit criminal acts.

\section{Research Sample}

It was decided that, for this research project, the top ten MMORPGs would be chosen on the basis of market share (see Table 1.1). To have used a comprehensive sample would have caused issues with data sampling due to the huge numbers of online games involved. The games that were chosen were also selected because of their use of gaming/ gambling within their remit. For each game, the registered head office was located as this is where the jurisdiction for the game and company originates. A game which may be played and marketed in country X may have its registered head office, and therefore legal base, in country Y. This is pertinent to the research project because of the nature of legal obligations emanating from the country of origin. The games that were chosen on the basis of their market share are listed in Table 1.1 next to their registered head office. There are two types of MMORPG: subscription based and freemium based. These are considered in correlation to each other with no distinction drawn at this stage.

The countries analysed in the research were chosen due to their connection with the research sample of games and their registered head office. Each country also plays an important part in the data analysis because of their overall interaction in global online gambling and gaming.

\section{Content Analysis}

Each MMORPG was tested against the definition of 'game of chance', which is the pertinent legal phrase under the UK's Gambling Act 2005, as defined in s.6. In order to ascertain whether the Gambling Act 2005 applied to each of the sample group of games selected within the research, a content analysis was carried out for each of the games, with every element of the legislation considered to determine whether the game falls within the regulatory grasp of the UK law. ${ }^{104}$ The findings are set out below.

104 All games are available in the United Kingdom. 


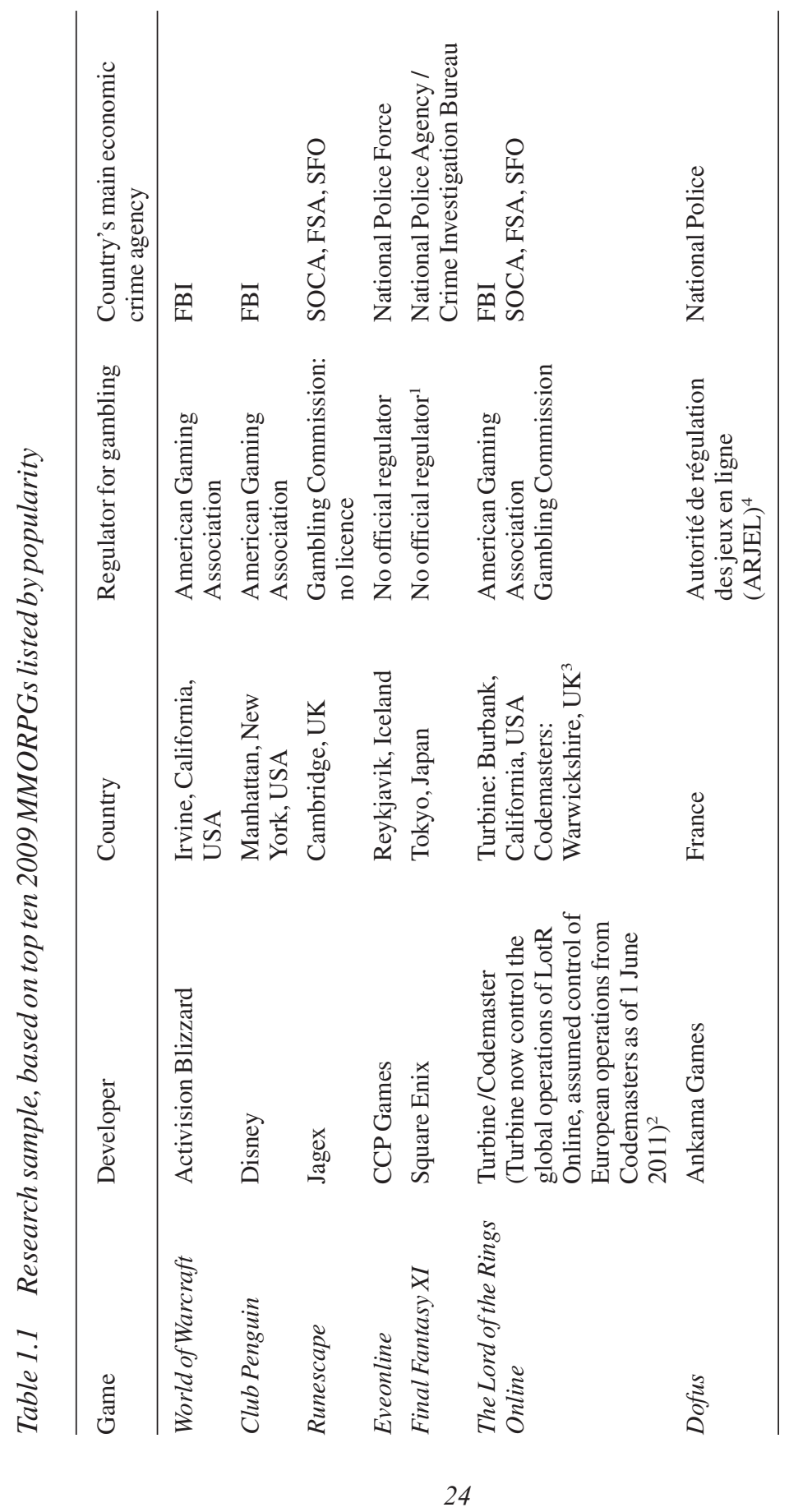




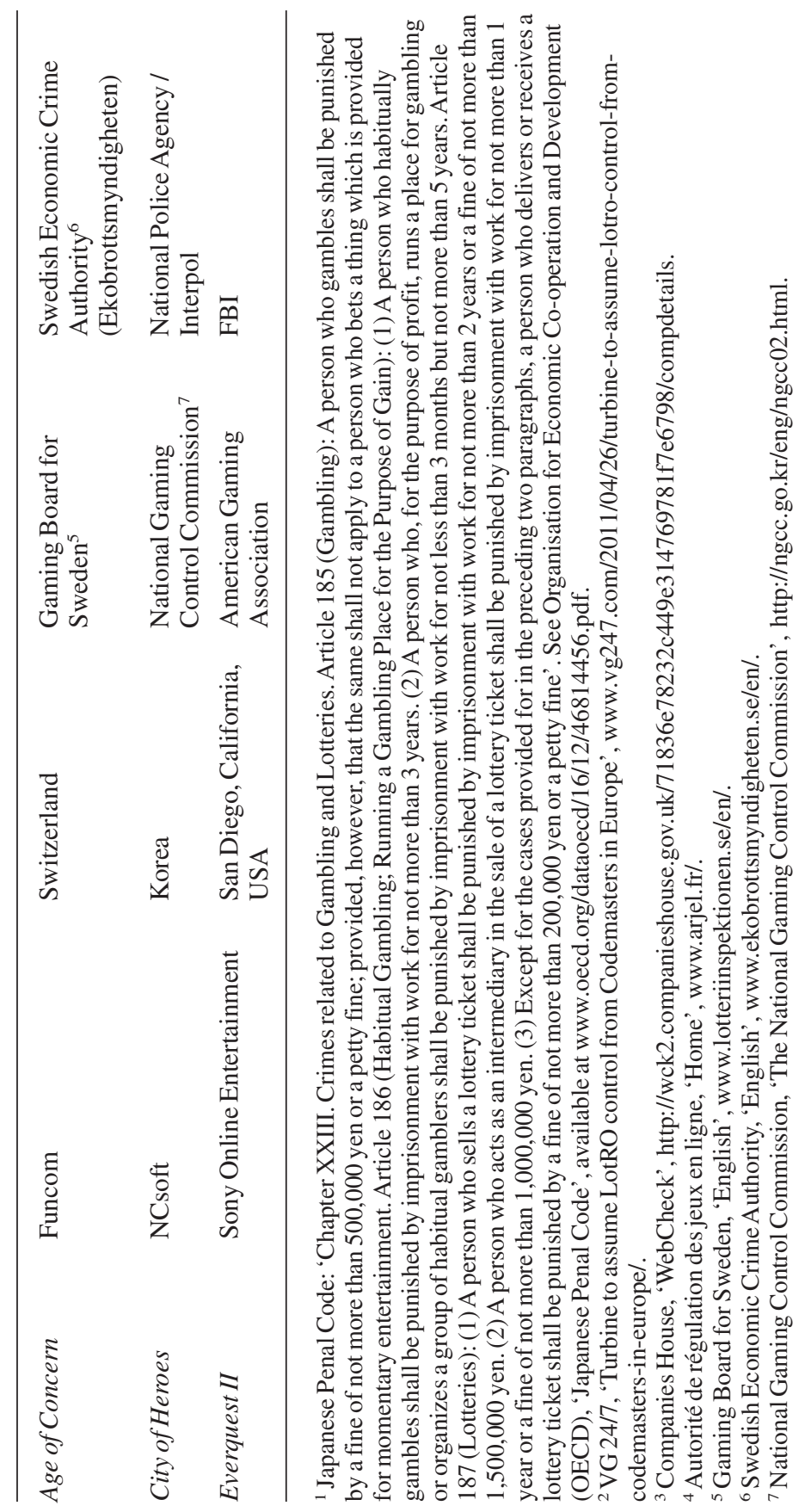




\section{World of Warcraft (WoW): Developer/Publisher: Blizzard Entertainment, ${ }^{105}$ subsidiary of Activision Blizzard ${ }^{106}$}

Gambling Act 2005, s.6(2): game of chance It could be argued that the game does satisfy s.6(2)(a)(i) and (ii). This is because players of the game can go on quests to carry out tasks and defeat enemies; these can involve fights with computer controlled opposition which can be won by chance (s.6(2)(a)(i)), or with skill (s.6(2)(a)(ii)). The question of applicability is in relation to the non-combat quests and whether there is chance or just progression through the game via doing the required task. If the latter were to be the case, then this would not be a game of chance as it is clear that 'if the player does this, they unlock this' and there is no element of luck, chance or skill. The section is harder to apply in combat situations: the moves of a human opponent cannot be entirely predicted; a skilled player would, through experience, have a good idea of the moves he/she will face from a character of the race and skill level of their opponent, and as such prepare for them, and this could be considered superlative skill. In relation to a game of chance, it could be said that in a combat situation a lesser skilled player will not have this knowledge and as such the game is more one of chance; he/she will win if the right moves for him to win happen to be made by his opponent.

Gambling Act 2005, s.6(3): participation The game satisfies the definition set out by the Gambling Act 2005, as players can play by themselves, or with other human controlled players (s.6(3)(a)), and will face computer controlled characters, referred to in most games as non-player characters (NPCs) (s.6(3)(b)).

Gambling Act 2005, s.6(4): plays for a prize Within this game, players play for the chance of winning items and 'levelling up' their character, thereby satisfying s.6(4)(a). Levelling up is the main means for character development; this is done through completing challenges known as quests in order to gain experience points. Levelling up occurs when enough experience points have been earned. Within the game players risk their character dying; they will 'respawn' but as a ghost, and must find their corpse in order to resurrect themselves, or use the in-game spirit healer. Using the spirit healer weakens the player's character for a period of time and weakens their items. This could satisfy 'losing something'

\footnotetext{
105 World of Warcraft, 'World of Warcraft', http://eu.battle.net/wow/en/.

106 Activision Blizzard, 'Activision Blizzard', www.activisionblizzard.com/ corp/index.html.
} 
under s.6(4)(b), but as stipulated in the subsection, this is not necessary to satisfy the definition of 'playing for a prize'.

Gambling Act 2005, s.6(5): prize Within the game, items acquired through games of chance and skill, and in some instances entire accounts that have been developed through gameplay, can be sold and exchanged for real money. ${ }^{107}$ This would give the prizes won in the game 'money's worth', thereby satisfying s.6(5)(a).

Based on the above, it can be concluded that WoW falls under the definition of a 'game of chance' under s.6 of the Gambling Act 2005. The wide definition of 'chance' presents a difficulty: it is not clear what constitutes 'chance', however, it would be hard for any game situation to be entirely predictable/down to skill, and this would possibly also detract from the activity being a 'game'. This is a trend with all the games analysed here: they all satisfy the wide definition of s.2. All of the games fuel online markets too, with the exception (in the most part) of Club Penguin. The presence of these markets, although not condoned by the game developers, gives the accounts and items in the games 'money's worth', satisfying the s.6(5) definition of a prize.

\section{Club Penguin: Developer: Club Penguin Entertainment; Publisher: Disney Online Studios ${ }^{108}$}

Gambling Act 2005, s.6(2): game of chance Club Penguin is a childfriendly MMORPG in which players create a penguin to play as. With their penguin, players play mini-games from which they earn in-game coins which enable them to buy items for their characters. While playing games, players also earn stamps for achievements in games, such as reaching level and point thresholds. The mini-games could be considered games of chance in that players do not know exactly the challenges they face but player skill can eliminate the element of chance. The games could satisfy s.6(2).

Gambling Act 2005, s.6(3): participation Players play many of the games alone but some games are multi-player; racing games, for example, can be played against other players. Players will meet NPCs too. Therefore, this game satisfies s.6(3).

107 Warcraft Loot, 'World of Warcraft (EU)', www.warcraftloot.net/buyaccounts/worldofwarcraft.

108 Club Penguin, 'Club Penguin', www.clubpenguin.com/. 
Gambling Act 2005, s.6(4): plays for a prize Players play in order to gain coins and stamps; stamps show their achievements in the minigames, coins are the in-game currency which allow players to buy items for their penguin. There does not appear to be any losses at stake; players lose lives within the mini-games and when these are exhausted the mini-game is over; there are no further penalties and the player then wins the amount of coins earned through their performance in the game. Within this game, money is entirely virtual - players can never withdraw the money. Money can only be made via external markets, which do exist.

Gambling Act 2005, s.6(5): prize Club Penguin accounts appear to be traded much less on Internet sites than other MMORPGs. Some attempts have been made at selling accounts (for example, one for US\$150, which for an account on what is marketed as a child's game seems a very high price). ${ }^{109}$ If accounts are sold for money online then they could be deemed to have money's worth and as such satisfy s.6(5). This is the only way this game can generate money, as virtual money within the game has no external value.

\section{RuneScape: Developer/Publisher: Jagex Game Studio ${ }^{110}$}

Gambling Act 2005, s.6(2): game of chance This game could be argued to satisfy s.6(2)(a)(i) and (ii). Players go on quests to carry out tasks and defeat enemies; these can involve fights with computer controlled opposition which can be won by chance (s.6(2)(a)(i)), or with skill (s.6(2)(a)(ii)). As with $W o W$, the quests are both combat and task-based; it could be argued here that the task-based quests are not games of chance as the player must go to the location and carry out the task, and will then unlock the content they pursue. The combat tasks within the game are more likely to be included under the s.6(2) definition; as with WoW, the skill of the player can change the degree of chance, which will be deemed superlative skill.

Gambling Act 2005, s.6(3): participation The game can be considered to satisfy s.6(3), as players can play by themselves, or with other human controlled players (s.6(3)(a)), and will face NPCs (s.6(3)(b)).

\footnotetext{
109 BUYPOE. 'Selling Club Penguin Account - From Beta', http://buypoe. com/buy/13368-selling-club-penguin-account-beta.html.

110 RuneScape, 'RuneScape', www.runescape.com/.
} 
Gambling Act 2005, s.6(4): plays for a prize Within this game, players play for the chance of winning items and levelling up their character, thereby satisfying s.6(4)(a). Players during gameplay risk their characters dying, however they will respawn with full health in 'Lumbridge' having lost all but three items that have previously been won. A gravestone will appear for two minutes, after which it will release the player's lost items. Prior to release, only the killed player can take the items, after the cracking of the gravestone the items can be picked up by other players or the gravestone can be repaired by players (this is less likely unless by a friend of the player). Additional settings/circumstances for respawn location and gravestone strength can be obtained, which still satisfies s.6(4)(b).

Gambling Act 2005, s.6(5): prize Items acquired and even entire accounts developed are sold for real money. ${ }^{111}$ This would give the prizes won in the game 'money's worth', satisfying s.6(5)(a). Although free to play, Runescape offers an ad-free package for a subscription fee; this, coupled with the sale of items and characters for real money, would suggest that the game satisfies s.6(5).

\section{EVE Online: Developer/Publisher: CCP Games ${ }^{112}$}

Gambling Act 2005, s.6(2): game of chance This game could be said to satisfy s.6(2)(a)(i) and (ii). Advancement in EVE is different to advancement in WoW and RuneScape; players train in skills and work on in-game professions, such as mining, piracy and fighting. The chance element is arguably satisfied by the random nature of items that can be procured from attacking other players, both computer operated and human players. Players may also take chances in the in-game economy, which operates under supply and demand, but can be manipulated by ramping and bear raids by organized groups of players; scams are an ever present risk within the game. Based on this, it is possible for EVE to satisfy s.6(2)(a)(i), and/or (ii) in that players attaining what they want can largely depend on the actions of other players, which, as in combat, cannot always be predicted, although a degree of predictive ability will come from experience.

111 Account Market, 'RuneScape Accounts', www.accountmarket.com/ Runescape-Accounts,category,2050,parent_id,categories.

112 Eve Online, 'Eve Online', www.eveonline.com/. 
Gambling Act 2005, s.6(3): participation The game can be considered also to satisfy s.6(3); players can attempt to isolate themselves if they wish but advancement can only really be achieved by integration with the markets and as such interacting with other players, fitting into s.6(3)(a). Players will also face NPCs, as described in s.6(3)(b).

Gambling Act 2005, s.6(4): plays for a prize Players may fight other players in order to steal their items; players can lose all their items and the ship they are flying. There are two types of loss: first, players may have their ship destroyed, in which case it ejects them in their 'escape pod' and they have to go to another of their ships (if possible); if not, they will need to obtain a new ship; a bookmark of the destroyed ship's location can be placed in order to return and recover what is left, but this is not usually much as other players may take items from the wreck. Secondly, a player may be 'podkilled', which is when they are destroyed in their escape pod; computer controlled players will not attack escape pods but human players will. If a player is 'podkilled', they are transported to whichever station at which they have their medical clone. As a penalty, 20 per cent of the difference in points between the clone's highest skill and the player's dead character will be deducted from that skill. Players must buy their medical clones and must also buy a new clone if they are 'podkilled', as they become their old clone. Players can be cautious by updating their clone frequently, essentially saving their progress. The losses the player suffers should satisfy s.6(4)(b), and the player risks these losses in order to gain items and in-game money for their ship, satisfying gains under s.6(4)(a).

Gambling Act 2005, s.6(5): prize Items acquired and even entire accounts developed are sold for real money. ${ }^{113}$ This would give the prizes won in the game 'money's worth', satisfying s.6(5)(a).

\section{Final Fantasy XI (FFXI): Developer/Publisher: Square Enix ${ }^{114}$}

Gambling Act 2005, s.6(2): game of chance This game could be considered to fulfil the gambling requirements under the Gambling Act 2005 to a lesser extent than other games, because the storyline is much more linear, but there are still various storylines to follow. To advance in rank and therefore access new areas and gain privileges, battles need to be

\footnotetext{
113 Player Actions, 'Eve Online', www.playerauctions.com/eve-isk/.

114 PlayOnline, 'Final Fantasy Online', www.playonline.com/ff11us/index. shtml.
} 
fought within the game. The majority of battles are against computer controlled characters, where fighting is based on a 'claim' and 'enmity' system. Attacking a monster, a computer controlled character 'claims' it as a player's team to fight, and players from other teams cannot attack the monster. The monster will then focus attacks on the player with the most 'enmity', which can be built up by players with the spells and abilities at their disposal. A foe is 'claimed' by taking aggressive action; once a player attacks an NPC, the NPC will only attack that player. Additionally, only that player or team-mates of that player may attack the NPC, which prevents interference from other players. 'Enmity' is the system by which NPCs select which players to attack - the player with the highest 'enmity' is targeted. 'Enmity is attributed to players based on their abilities, level, items and previous game behaviour'. Based on these fights, there is an element of chance in that a player may or may not be attacked; this risk can be reduced by the skill of the player. The element of chance comes from the relative unpredictability of the computer controlled characters and what will be dropped by them in fights, but both of these things are likely to become predictable from continued play and the widespread use of forums in gaming. Based on this, Final Fantasy XI could fit the definition of game of chance under the Gambling Act 2005.

Gambling Act 2005, s.6(3): participation Players can play the story on their own, but it is easier with other players as it is more effective to fight monsters in conjunction with other players. During the fight, the aim is that the monster will be defeated more quickly. Additionally, the 'enmity' system provides protection for weaker players. In light of this, it could be argued that FFXI will fit within s.6(3).

Gambling Act 2005, s.6(4): plays for a prize Players play to win items and to level up their character; they do this by performing missions and quests. Should their character die on these quests, they will lose 10 per cent of the experience points required to get to the next level. If losing these points takes the player below the total they need, then they will go down a level. The player may stay at the location they are at in the hope they are revived by a team-mate or they can return to their home point to respawn. The player can wait a maximum of 60 minutes at the location they died before being automatically returned to their home point. These circumstances fit s.6(4), as players play for the prizes at the risk of losing experience points and being moved away from the location of the prizes. 
Gambling Act 2005, s.6(5): prize A prize in FFXI is likely to constitute a prize under s.6(5), as it could have money's worth; accounts and items are bought and sold for real money on trading sites. ${ }^{115}$

\section{The Lord of the Rings Online: Developer/Publisher: Turbine ${ }^{116}$}

Gambling Act 2005, s.6(2): game of chance Advancement through the game is achieved through completing quests known as 'Chapters', contained in a series of 'Books'. By doing this the player gains experience points, which in turn increase the level of the character. This improves the character's abilities but new skills can be bought with in-game currency from NPCs. There is also a player versus player ( $\mathrm{PvP})$ mode to the game; this is known as 'Monster Play' and is unlocked when a player's character reaches level 10. Characters can play as a level 75 'Monster', or if they continue to develop their character they can play as a level 40 'Hero'. The mode works as a constant battle for territory between Heroes and Monsters. Players attack opposing players and in the process gain experience. Raids in 'Monster Play' could be argued to fit within s.6(2)(a)(ii) in that there are elements of chance which can be eliminated by skill, as players do not know the moves that will be made by their opponent but can be confident of victory if their character is a higher level or they are a more experienced player.

Gambling Act 2005, s.6(3): participation Playing the game would satisfy s.6(3), both in playing alone or interacting with others (s.6(3)(a)) and playing against the NPCs (s.6(3)(b)).

Gambling Act 2005, s.6(4): plays for a prize Players play to advance the level of their character, gain coins and with these coins purchase skills and items. This is done through quests and raids which pose the risk of death for the player's character. The death of a player's character results in a temporary drop in skill levels, making the player weaker. Additionally, the player must pay to repair their character's armour using in-game currency, which becomes more expensive the higher the value of the items worn. This basis for playing could satisfy s.6(4).

Gambling Act 2005, s.6(5): prize A prize in the game could be experience points or items dropped by felled NPCs. These can be added to a character and money gained in the game can be used to buy skills. These

\footnotetext{
115 Gamewar, 'FFXIV Accounts', www.gamewar.com/buyaccounts/ffxiv.

116 Lord of the Rings Online, 'Lord of the Rings Online', www.lotro.com/.
} 
are arguably of money's worth as they can be bought and sold for real money on various sites. ${ }^{117}$

\section{Dofus: Developer/Publisher: Ankama Games ${ }^{118}$}

Gambling Act 2005, s.6(2): game of chance Within this game, a player controls a character and increases its level by gaining experience points. Experience points are gained from defeating monsters and completing quests. Levelling up gains more spells and life points for their character. Players obtain experience from quests and from combat, which could be deemed as a game of chance which can be eliminated by skill; players can be defeated by other players (both player controlled and non-player controlled) but the chance of this can be reduced by player skill. This gameplay could satisfy s.6(2)(a)(ii).

Gambling Act 2005, s.6(3): participation Playing the game would satisfy s.6(3), both in playing alone or interacting with others (s.6(3)(a)) and playing against the NPCs (s.6(3)(b)).

Gambling Act 2005, s.6(4): plays for a prize Players play in order to gain experience points and collect/buy items; these are traded within the in-game economy. Players risk their character being killed which results in a loss of energy, the players character then respawns at the exit of the tutorial area. If the character's energy becomes too low, they must find a 'Special Spring' to regenerate their energy. This gameplay will satisfy s.6(4).

Gambling Act 2005, s.6(5): prize Experience points, items and levelled up characters could be deemed as prizes; these have virtual worth and with the existence of an online market they can be bought and sold for real money ${ }^{119}$ and as such have money's worth.

\section{Age of Conan: Developer/Publisher: Funcom ${ }^{120}$}

Gambling Act 2005, s.6(2): game of chance Players create a character to play as through the game. With their character, they can complete quests to level up their character and battle other players. Quests and combat

\footnotetext{
117 AccountGear.com, 'Sell or Trade Your Account - Lord of the Rings', www.accountgear.com/sell/Lord-of-the-Rings.

118 Dofus, 'Dofus', www.dofus.com/en.

119 GGDER, 'DofusAgride', www.ggder.com/Dofus-Agride/.

120 Age of Conan, 'Age of Conan', www.ageofconan.com/.
} 
could be defined as a game of chance under s.6(2), in that the moves of the other characters in the game cannot always be predicted, but superlative skill as a character can eliminate this chance element and ensure they have the power to defeat their enemy or complete the current quest before engaging.

Gambling Act 2005, s.6(3): participation Players can play largely alone, but will advance more quickly playing with others, and will face NPC enemies during play. This gameplay will satisfy s.6(3).

Gambling Act 2005, s.6(4): plays for a prize Players complete quests in order to acquire items and experience points; gaining enough experience points levels up their character. These goals are pursued at the risk of their character dying; should this occur the character will respawn as a ghost, and the player must either find their character's body at the location it was killed and resurrect it, or take a temporary health and attribute penalty to be resurrected by a computer-controlled healer. This could satisfy s.6(4).

Gambling Act 2005, s.6(5): prize Prizes on the game have virtual worth, and with the existence of trading websites ${ }^{121}$ can be attributed money's worth and therefore fulfil s.6(5).

\section{City of Heroes: Developers: Paragon Studios ${ }^{122}$ and Cryptic Studios; ${ }^{123}$ Publisher: NCsoft ${ }^{124}$}

Gambling Act 2005, s.6(2): game of chance Similar to other MMORPGs, players level up by defeating enemies, completing missions and exploring the environment. Players exploring the environment will stumble upon items and enemies by chance. Again, like other MMORPGs, players can eliminate the element of chance with skill, satisfying s.6(2)(a)(ii).

\footnotetext{
121 Gamewar, 'AOC Accounts', www.gamewar.com/buyaccounts/aoc.

122 City of Heroes, 'City of Heroes: Freedom', http://na.cityofheroes.com/en/.

123 Ibid.

124 Ibid.
} 
Gambling Act 2005, s.6(3): participation The wide definition of participation in s.6(3) is satisfied, as players can carry out missions alone or with other players, and during gameplay players will come across NPCs.

Gambling Act 2005, s.6(4): plays for a prize Players play through the missions and fight with their characters in order to gain experience points which can level up their character and improve their character's skills. If the player's character dies during gameplay they suffer an experience point penalty which slows character development, making it undesirable to die often. Virtual prizes are given for in-game achievements which are pursued at the risk of dying, and this could satisfy s.6(4).

Gambling Act 2005, s.6(5): prize Accounts and items won in-game are sold for real money on websites, giving them money's worth, ${ }^{125}$ satisfying s.6(5).

\section{EverQuest II: Developer/Publisher: Sony Online Entertainment ${ }^{126}$}

Gambling Act 2005, s.6(2): game of chance As with the other MMORPGs in the list, players create a character and progress through the game by levelling up the character; this is done primarily through quests, of which there are over 6,000. Players may also enhance their character by exploring the environment by combat. Players can add more valuable items to their character as they level up and acquire them.

Gambling Act 2005, s.6(3): participation Players play the game either on their own or, more commonly, with other players, they also face NPCs. This will satisfy s.6(3).

Gambling Act 2005, s.6(4): plays for a prize Players play to develop their character and collect items for that character. In doing this there is the risk of their character dying in the game. Upon death, characters respawn, with all their items, at specific revival locations, although characters do suffer a minor 'experience debt' which must be repaid. After ten deaths items need to be repaired to 100 per cent for an in-game fee.

\footnotetext{
125 AccountsGear.com, 'Sell or Trade Your Account - City of Heroes', www.accountgear.com/sell/City-of-Heroes.

126 EverQuest II, 'EverQuest II', http://everquest2.com/.
} 
Gambling Act 2005, s.6(5): prize Prizes have virtual worth in the game but can have money's worth as a result of websites trading game accounts and items, ${ }^{127}$ satisfying s.6(5).

From the above content analysis of the top ten games included within this research, it can clearly be seen that each of them fulfil, in most part, the requirements laid down by the Gambling Act 2005 for remote gambling.

\section{OUTLINE OF CHAPTERS}

Chapter 2 of the book provides a detailed critical literature review of cyber law, examining different theories and perceptions of cybercrime. It also includes an analysis of the existing law enforcement agencies in the United Kingdom who deal with cybercrime.

Chapter 3 explores global and virtual gambling legislation, looking at different issues associated with gambling, such as remote, virtual and economic crime. The chapter also contains empirical research arising from content analysis of legislation in the United Kingdom, United States of America and Korea.

Chapter 4 explores the international measures to regulate online gambling, starting with an overview of the European Green Paper on Gambling aimed at harmonizing laws across Europe. Commonwealth cybercrime law is also discussed, drawing from the European Convention on Cybercrime, which aims to provide a benchmark for other countries. In each of these chapters, the authors are critical of the perception of gambling in virtual worlds and the Internet and argue that it is largely ignored and not regulated. It is a hidden area that seems to be forgotten, whether deliberately or not.

Chapter 5 explores virtual financial crime legislation in the United Kingdom, United States of America and Korea.

Chapter 6 looks at a different aspect and explores the world of digital currencies, which can be used within the virtual world, Internet and games and therefore fall within the issues discussed in this book. Real-world money is not the only means of gambling and/or committing financial crimes within the virtual environment. As such, several high profile cases will be explored against the backdrop of potential further issues that legislators and law enforcement agencies need to consider.

127 Gametag, 'EverQuest 2', www.gametag.com/buyaccounts/EverQuest-2. 
The book concludes with the summary and recommendations in Chapter 7, which focus on looking to the future towards joined up regulation which recognizes and acknowledges the new forms of technology-enhanced criminal activity. 